Europe's Journal of Psychology, 7(3), pp. 419-442

www.ejop.org

\title{
Personal and situational values predict ethical reasoning
}

\author{
Micha Strack \\ Georg-August-Universität Göttingen, Göttingen, Germany
}

\section{Carsten Gennerich}

Evangelische Hochschule Darmstadt, University of Applied Science, Darmstadt, Germany

\begin{abstract}
In interpersonal value conflicts ethical principles are employed to justify own actions. However, there is competition among ethical principles. Therefore the preference for a specific ethical principle may be merely a function both of personal values and of the value-laden situations in which actions are made. A German sample of 132 participants rated their agreement on ten justifications in seven experimentally constructed situations. The situations varied in their expression of values, organized by the value circle (Schwartz, 1992). The justifications assess five ethical principles (deontology, utilitarianism, partiality, hedonism, and intuitionism). Variance components of the agreement ratings were separated using GLM and plotted in the value circle. Preferences for ethical principles depended on both the value content of situations and the responder values. The Person $x$ Situation interaction was not significant. The results illustrate the difficulties in gaining agreement on arguments among individuals with conflicting values.
\end{abstract}

Keywords: values, moral reasoning, person-situation interaction.

People endorse different values that they consider to be important. These values can be in conflict with each other and accordingly people decide to give priority to some values over others (Schwartz, 1992, 2011). Research on people's reasons for endorsing certain values shows that argumentative support in the sense of cognitive elaboration on sound principles and good causes can foster endorsement of values and increase the likelihood of behavior in accordance with these values (Bernard et al., 2003a). However, people do not always have argumentative support for their 
values and are vulnerable to the attack of their values (Bernard et al., 2003b). Therefore, in situations in which values are under discussion, argumentative support is crucial (e.g., Cherry \& Faedrich, 2002 in business ethics, Candee, 1984 in medical ethics). In the philosophical tradition, philosophers conceptualize categories of reasoning which intend to establish a basis for agreement independent of certain value positions, i.e. so called ethical principles (Beck, 1989; Larmore, 1987). However, ethical principles as patterns of reasoning are rarely addressed by psychological research (cf. Cherry \& Fraedrich, 2002).

Evidently, individuals justify their actions and value decisions using various methods of ethical reasoning (e.g. Maio \& Olson, 1998). As moral philosophy has systematized possible prototypes of moral reasons on the level of ethical principles, people's ethical reasoning can also be categorized by these principles. When a person says, "the outcome is best for everyone", utilitarian reasoning can be identified. A Kantianist would prefer to say "it's our duty to act like this", where the particularist says "in my particular situation I have to do this". Even the self is perceived as a value base and a moral good in modern Western societies (Baumeister, 1989). In consequence, hedonistic reasons are perceived as legitimate ("I just like to consume this") and have been elaborated in moral philosophy (Stirner, 1995). Therefore, it is possible that all moral or justifying arguments belong to the area of ethical reasoning and can be identified as examples or blends of prototypical ethical principles. However, the question as to what determines the lay person's choice among ethical principles in reasoning remains open and will be addressed in this study.

Conceptually, the principles people refer to in the process of ethical reasoning can be related to the individual's personality, the social situation or both. 1) According to Rohan (2000), ethical principles appear in everyday life in the form of individually represented value-laden constructs which he called ideologies. Ideologies vary across social groups and personalities. 2) From the perspective of classical social psychology (e.g., Asch, 1955; Milgram, 1963), the preference for an ethical principle should be determined by the social situation. 3) The third option - the scenario applied in this study - is a blending of influences from both the persons involved and the situation at hand. While only preliminary attempts have been made to address these questions empirically (Witte \& Doll, 1995; Gollan \& Witte, 2008), there exists a good deal of psychological research on value preferences (Rokeach, 1973; Schwartz, 1992, 2011) and some independent work on the assessment of the usage of ethical principles (Fraedrich, \& Ferrell, 1992; Forsyth \& Nye, 1990; Witte \& Doll, 1995). 
Personal Values

Values were posited by Rokeach (1973) as the primary content of an individual's identity. According to Rokeach, values function as cognitive standards for individual actions. He contends that values are universal but are differentially esteemed. In addressing the structure of values, Schwartz and Bilsky (1987) hypothesized universal conflicts in the content of values. In 1992, Schwartz documented research in 20 countries which led to a bipolar structure of 56 rated values in two orthogonal dimensions of self-transcendence vs. self-enhancement and openness to change vs. conservation. The resulting circle of values represents the relativity of values: incompatible values are plotted far away from one another and similar ones are plotted in close proximity (Schwartz, 1992, 2011). The upper part of the value circle expresses self-transcendence and is made up of universalistic values and benevolence, followed clockwise by tradition, conformity and security values (conservation), power and achievement (self-enhancement), hedonistic values, stimulation and selfdirection (openness to change).

Figure 1: Value circle (14-Bipolar-Short-Form; Strack, 2004)

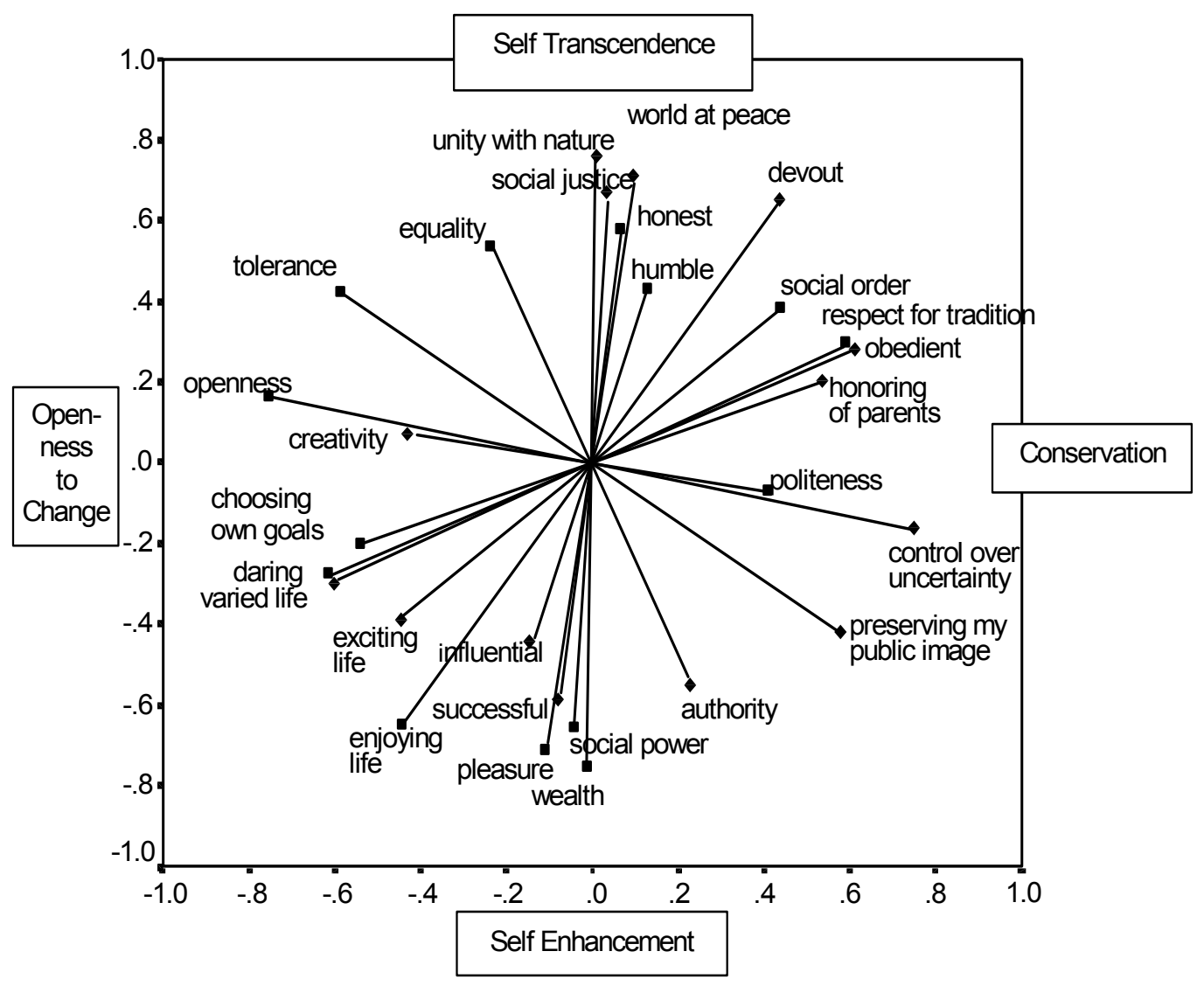


To assess the value preferences of individuals participating in this study, we used a short questionnaire with 14 bipolar rating items (Strack, 2004), utilizing the empirical content structure of the Schwartz value circle (see Figure 1 and Appendix 2).

Situational Values

Just as individuals vary in personality traits, motives or value preferences, real situations differ in certain (mostly unknown) dimensions and can be categorized into various classes. Gollan and Witte (2008) relate value laden situations to Heider's concept of situational ought (1958). We further assume that the content structure of values that Schwartz (1992) found in the variance between individuals can also be applied to the variance between situations. For example, the experiments in early social psychology can be interpreted as powerful demonstrations of value-laden situations: Conformity presses (Asch, 1955) and compliance demands (Milgram, 1963) lead to actions of conformity and obedience. Conformity and obedience may be seen as values within the experimental situations. In some later studies, participants were asked directly to express which values might be appropriate in different situations (Feather, 1990; Heath, 1976). As Feather (1990) shows, strong situations may override the effects of individual value differences. Action in accordance with situational values, activated by vignettes, usually induce less regret than a mismatch of personal and situation values (second study in Lönnqvist et al., 2006). However, as situational values and the approach of interactionism have been given little attention in psychological value research, we will state our hypotheses on personal values and situational values separately.

\section{Ethical principles}

As Maio and Olson (1998) show, lay people normally do not reflect on their values and value-based decision-making in everyday life. However, when people are aware of conflicting values and when argumentative support is demanded by the situation, they are able to justify their position and to relate their values to moral reasons (i.e., Maio \& Olson, 1998; Tetlock, 1986). Moral philosophy, on the other hand, elaborates possible justifications for such value-laden actions. Philosophers claim to have identified all conceivable moral reasons on the level of ethical principles (Larmore, 1987). Therefore, while we expect that people's own moral reasons may be less clearly elaborated, these reasons can nevertheless be fully described by the prototypes of ethical principles clarified in moral philosophy.

Within social psychology, attempts have been made to operationalize these principles. Best known is Forsyth's (1980) taxonomy of ethical principles. Combining high or 
low relativism with high or low idealism, he postulated four types of ideologies: situationism, absolutism, subjectivism and exceptionism. He validated his Ethics Position Questionnaire with individual differences from the domain of moral judgments and attitudes (Forsyth \& Nye, 1990; Hadjistavropoulos et al., 2003); for example, Machiavellian subjects are more relativistic and less idealistic whereas subjects endorsing an ethic of caring are highly idealistic and non-relativistic (Forsyth et al., 1988). It is, however, not easy to relate the resulting categories to the ethical principles elaborated in moral philosophy (Strack \& Gennerich, 2007). More in line with moral philosophy, Witte and Doll (1995; Gollan \& Witte, 2008) proposed taxonomy of four principles: utilitarianism, deontology, intuitionism and hedonism. The results of their study show that ethical positions depend on the situation (they used vignettes of positive/negative and individual, interpersonal, and social impact situations). Although they did not explore values, they additionally found differences between East- and West-German participants. Their study encourages research on the influence of personal and situational determinants of ethical principles (see the review in Gollan \& Witte, 2008). Based on this research, we distinguish the following five principles:

Utilitarianism we define with Larmore (1987) based on the principle of consequentialism; i.e., a person must choose that action which leads to the optimum positive outcome for all concerned. Because this principle aims at the optimum for all, it clearly favors self-transcendent values. On the other hand and with reference to the value dimension of openness to change vs. conservation, it can lead to actions in conflict with tradition, because the criterion of utility is basically ahistorical.

Deontology subscribes to the classical Kantian categorical imperative: "Act only according to that maxim by which you can at the same time will that it should be a universal law" (Beck, 1989). It should be emphasized that deontology primarily demands that certain actions never be taken, regardless of the consequences (Larmore, 1987). Therefore deontology might favor conservative actions, as the range of justifiable actions is limited in comparison to the utilitarian principle. Fraedrich and colleagues (Cherry \& Fraedrich, 2002; Fraedrich \& Ferrel, 1992) provide some empirical evidence that deontologists are less influenced by negative consequences for themselves in comparison to egoists and utilitarianists, and deontological reasons are preferred under higher risk. As the perception of risks is related to values of conservation (Jost et al., 2003), we predict deontology to be related to values of tradition and security.

In earlier research, partiality was discussed in practical ethical reasoning but was not yet recognized as a distinct basic principle. It was first introduced as such in moral philosophy by Larmore (1987). He defined partiality as being grounded in particular- 
istic duties evoked by personal promises and bonds. In everyday life, such bonds are primarily based in family relationships where universalism is restricted. Therefore, the principle of partiality should relate to values of security between the poles of conservation and self-enhancement.

Hedonism as an ethical principle was defined by Witte and Doll (1995) as being focused on personal consequences; thus, social norms should not be in conflict with the welfare of the individual (Parfit, 1984). This ethical orientation toward the self was first and less moderately elaborated by Stirner (1995), who based his theory on egoism stating that other people are the objects of personal consummation. "Because this is best for me" is an example of a hedonistic justification. Because of the founding principle of egoism, this ethical principle relates to self-enhancement values.

Intuitionism was defined by Witte and Doll (1995) as the limitation of duty by emotional experience, as exemplified in their intuitionism sample statement, "I simply have to act in this way!" Intuitionism is thus based on a person's subjective sense of morality and represents their inner direction, which Riesman (1950) relates to liberalism. Therefore, this principle should be primarily related to self direction values.

When linking the concept of values with that of ethics, similarities between ethical principles and the semantics of the Schwartz (1992) value circle appear. To examine our assumption that ethical reasoning and values are not independent, we hypothesized correlations of value orientation with the ethical principles as follows:

Hypothesis 1 (personal values hypothesis): Ethical reasoning depends on the value preferences of the reasoning subject. Individuals with universalistic values were predicted to prefer the utilitarian principle of consequentialism. Individuals with traditional values were predicted to prefer the principle of deontology. Persons with a value orientation toward security were predicted to prefer the principle of particularity. Persons with self-enhancing values were predicted to prefer hedonistic justifications. Finally, the intuitionism principle should be preferred by individualist persons with self-direction values (i.e., openness and tolerance, see Figure 1).

Hypothesis 2 (situational values hypothesis): The choice of an ethical principle depends on the values demanded by the situation. The principles of utilitarianism will be activated in situations in which universalistic values motivate self-transcendent actions. Reactions to situations honouring traditional values were expected to be justified with deontological ethics. Situations which induce security values were expected to activate particularity, and actions based on situational self-enhancing values were expected to be justified with hedonistic reasoning. The choice of intu- 
itional reasoning is likely in situations promoting self direction.

Therefore, we expect personal values and situational values to be specifically related to ethical principles. As stated in hypotheses 1 and 2, we expect personal valves and situational values pointing to the same content to be functionally equivalent (i.e. work in the same direction). The principle of functional equivalence was initially proposed by G. W. Allport (1959) to explain traits as the bases for actions and as the principles for perceiving different situations as equivalent opportunities to express the traits. The functional equivalence of personal and situational factors was elaborated by Schmitt and colleagues (Schmitt et al., 2003; Schmitt \& Sabbagh, 2004) in the domain of justice research. According to them, personal and situational factors are functionally equivalent if they affect a given outcome similarly and are thus substitutable in their effects. Schmitt at al. $(2003,2004)$ further proposed that functionally equivalent person and situation factors amplify their effects: a synergistic interaction will appear.

Hypothesis 3 (interaction hypothesis): If hypothesis 1 and hypothesis 2 both become accepted, then personal value preferences and situational value activation with content equivalence will constrain justifications in a functionally equivalent way. Therefore the agreement on ethical principles will additionally depend on a synergetic person x situation interaction. For example, within a situation that generally activates universalistic values (and therefore utilitarian justifications of selftranscendent actions according to hypothesis 2), the personal value preference for universalistic values should effect the preference of utilitarian justifications more (with a higher slope) than was expected by the additive effects of the situation and the person alone.

\section{Method}

\section{Overview and Procedure}

The hypotheses propose main and interaction effects of personal and situational values which are structured by the values circle. Personal values are usually assessed by abstract value statements. To maintain the completeness of the values circle also for the second independent variable, the situations, we decided to transfer this high level of abstraction to the situational values as well. Each situation was therefore described in a vignette as an imaginary own action based on the value categories of the Schwartz' values circle. After reading each of the vignettes, the participants were asked to rate the applicability of 10 statements that outline the five ethical 
principles to justify his or her actions given in the vignette. Seven vignettes with systematic value content were varied within each subject.

Participants

Our intent was to recruit a heterogeneous non-academic sample to maximize variance in personal values and life experiences (ordinary people, so to speak). Therefore, we asked students and acquaintances to distribute the questionnaires to people not related to the university. 132 individuals living in Germany participated in the study. The return rate of the distributed questionnaires was $66 \%$. The age of participants varied from 16 to 77 years $(M=41, S D=17)$; $60 \%$ were female and $40 \%$ male; $58 \%$ lived in the western part of Germany, and $42 \%$ in the eastern part. Twelve percent of participants had a relatively low level of education (9 years), $47 \%$ a moderate level (10 years), and $38 \%$ a higher level of education (12-13 years).

\section{Materials}

Valve-laden situations. Seven vignettes (see appendix) were experimentally constructed to evoke abstract but value-laden situations representing the content structure of the Schwartz value circle (Figure 1). Each vignette presents an abstract social situation in which two values are in conflict (values at opposite sides of the circle), and the actor in the vignette honours one of them. The responder was invited to identify herself or himself with the actor in each situation and respond with her or his personal explanation for the adopted position. Although we were aware that participants might find it more difficult to identify with actors in abstract situations, the stories were purposely kept abstract in order to assure that each situation represented a distinct value area and evoked situational demands of comparable "strength". The situational vignettes seem to contain the same level of abstraction as is common in the assessment of personal values. Each participant worked on each of the seven vignettes. The fixed sequence began with the situation representing a universalistic position and continued with positions representing values, in a counterclockwise direction, in the Schwartz value circle (see Figure 1), ending with a benevolence position (see appendix 1).

Ethical principles. Each of the five ethical principles (deontology, utilitarianism, partiality, hedonism, and intuitionism) was assessed using two statements (see appendix 1). The ten statements were formulated according to the theoretical definitions given above. Each statement was rated for agreement on a five-point scale ranging from 1 (rather no, rather would not use) to 5 (rather yes, rather would use). To control the sequence effect of the ten statements, four random sequences were 
produced and varied between subjects. The mean of the single items range from $M$ $=2.90$ to 3.57 with SD from 1.00 to 1.11 . In the raw data, the two-item scales show moderate reliabilities acceptable for the purpose of this study (Cronbach's Alpha: deontology $\alpha=.67$, utilitarism $\alpha=.71$, partiality $\alpha=.60$, hedonism $\alpha=.53$ and intuitionism $\alpha=$.67). Therefore the two statements were averaged for each principle.

Personal values. The personal value preferences of the participants were assessed by the 14BiPole-Value questionnaire (Strack, 2004; see appendix 2). It was developed from a German sample of 535 respondents to the Schwartz Value Survey. The questionnaire combines 26 of the values given in the Appendix in Schwartz (1992), supplemented by two new values ("Open to the world (cosmopolitan, enjoying variety)", and "Control over uncertainty (to retain control)") in 14 bipolar items. Participants had to decide toward which of two competing values they tended to orient themselves; e.g., they chose between "Equality (equal opportunity for all)" and "Authority (the right to lead or command)" on a bipolar five point scale. We revealed the circular structure for the participants by factor analysis (PCA). The factors (43\% item variance declared) nicely resemble the dimensions "conservation vs. openness to change" and "self-transcendence vs. self-enhancement" (see Figure 1). The participants completed the 14BiPole-Valve questionnaire before working on the seven vignettes dealing with situational values and ethical principles.

\section{Results}

To test the validity of the three hypotheses, we analyzed the variance of the agreement scores. In the experimental $7 \times 5$ within subject design (seven situations, five ethical principles), the participants' scores on the two dimensions of the value circle (the personal values) were included as covariates. The covariates were allowed to interact with the experimental factors. Each agreement score is therefore expressed by a linear equation with 12 sources of variance (see Table 1).

The constant source (source 1 in Table 1) states that respondents generally agree with the given ethical justifications (overall mean $=3.33$ on the five-point scale). The person main effects (sources 2 and 3 in Table 1) state that participants, who prefer benevolence values (conservation and self-transcendence), tend to express higher agreement with all given ethical justifications. The full factorial design assures the control over this mere leniency effect. 
Table 1: Experimental $7 \times 5$ Within-subject Design with Personal Value Preference (Dimensions: Self-Transcendence and Conservation, see Figure 1) as interval Predictors on Agreement with five Ethical Justifications in seven Situations

\begin{tabular}{|c|c|c|c|c|c|}
\hline \multicolumn{2}{|c|}{ Source } & $\eta^{2}$ & $d f$ & $F$ & $p$ \\
\hline \multicolumn{2}{|c|}{ 1) Constant } & .97 & 1,122 & 4311.8 & $<.001$ \\
\hline & \multicolumn{5}{|l|}{ Person } \\
\hline 2) & Self-Transcendence & .08 & 1,122 & 10.92 & $<.001$ \\
\hline 3) & Conservation & .02 & 1,122 & 3.19 & .08 \\
\hline \multicolumn{2}{|c|}{ 4) Situation } & .28 & 6,117 & 8.26 & $<.001$ \\
\hline & \multicolumn{5}{|l|}{ Person $X$ Situation } \\
\hline 5) & Self-Transcendence & .28 & 6,117 & 7.71 & $<.001$ \\
\hline 6) & Conservation & .08 & 6,117 & 1.84 & .10 \\
\hline \multicolumn{2}{|c|}{ 7) Ethics } & .45 & 4,119 & 24.65 & $<.001$ \\
\hline & \multicolumn{5}{|l|}{ Person $X$ Ethics } \\
\hline 8) & Self-Transcendence & .06 & 4,119 & 1.91 & .12 \\
\hline 9) & Conservation & .08 & 4,119 & 2.58 & .05 \\
\hline \multicolumn{2}{|c|}{ 10) Situation $X$ Ethics } & .45 & 24,99 & 3.41 & $<.001$ \\
\hline & \multicolumn{5}{|c|}{ Person $X$ Situation $X$ Ethics } \\
\hline 11) & Self-Transcendence & .16 & 24,99 & 0.78 & .75 \\
\hline 12) & Conservation & .16 & 24,99 & 0.80 & .73 \\
\hline
\end{tabular}

The situation's main effect (source 4 in Table 1) states that the seven situation vignettes obtain different agreement scores over all the ethical principles (effect scores for situations range from -0.32 to +0.19$)$. The within-cell variance of the situation main effect correlates significantly with the participant's values (source 5 and 6 in Table 1) and can be interpreted as a manipulation check: a situation expressing a certain value area of the value circle should gain more agreement for all its justifications from participants preferring the equivalent personal values. Figure 2 illustrates the correlation of the participant's values with the participant's situation effect scores. 
Figure 2: Correlation of person's values with person's agreement per vignette (part of variance due to person $x$ situation on general agreement: sources 5 and 6 in Table 1;

$$
\mathrm{N}=132 \text { ) }
$$

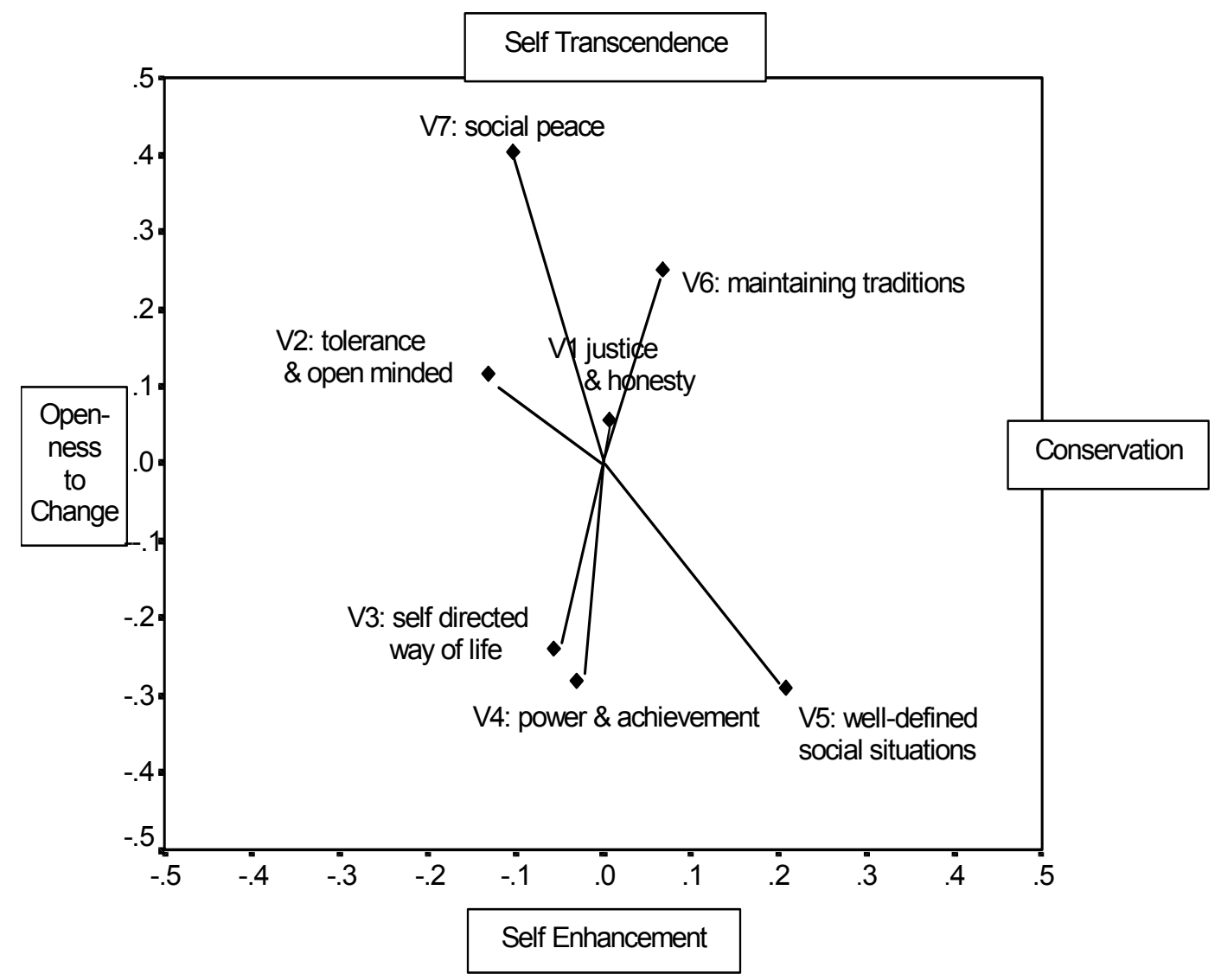

Note: $\mathrm{V}=$ vignette

Situations expressing self-transcendence values got higher overall agreement from subjects with self-transcendent values and therefore are located in the upper part of Figure 2 (Vignettes 1 and 7, see appendix 1). The vignette in the first position of the questionnaire (1) did not work well - its correlation remains low. Maintaining traditions (6) is consistent related to self-transcendence values and conservation. The position dealing with well-defined social situations (5) obtained the strongest agreement from participants with security values. Concern for achievement (Vignette 4) obtained the strongest agreement from self-enhancement persons. The values of a self-directed life were related more to self-enhancement than to openness to change but are still in the correct quadrant compared to the content structure of the value-circle in Figure 1. Tolerance and openness (Vignette 2) were related to values in the area of self-direction. The correlations depicted in Figure 2 are inter- 
preted as the value content of each situation and are used as numerical weights for the second hypothesis (see below).

The main effect of the ethical principles (source 7 in Table 1) states that the five ethical principles gain different agreement scores (effect scores range -0.42 to +0.25, with the most agreement for utilitarianism and the least for deontology). The first hypothesis stated that ethical reasoning depends on a participant's value preferences. Figure 3 shows the correlations of the within-cell variance of the agreement with each of the five ethical principles (this within-cell scores can be computed for each subject according to the GLM procedure formulas) with the personal values (source 8 and 9 in Table 1).

Figure 3: Correlation of person's values with person's agreement per ethical principle (part of variance due to person $x$ ethical principles: sources 8 \& 9 in Table 1; $N=132$ )

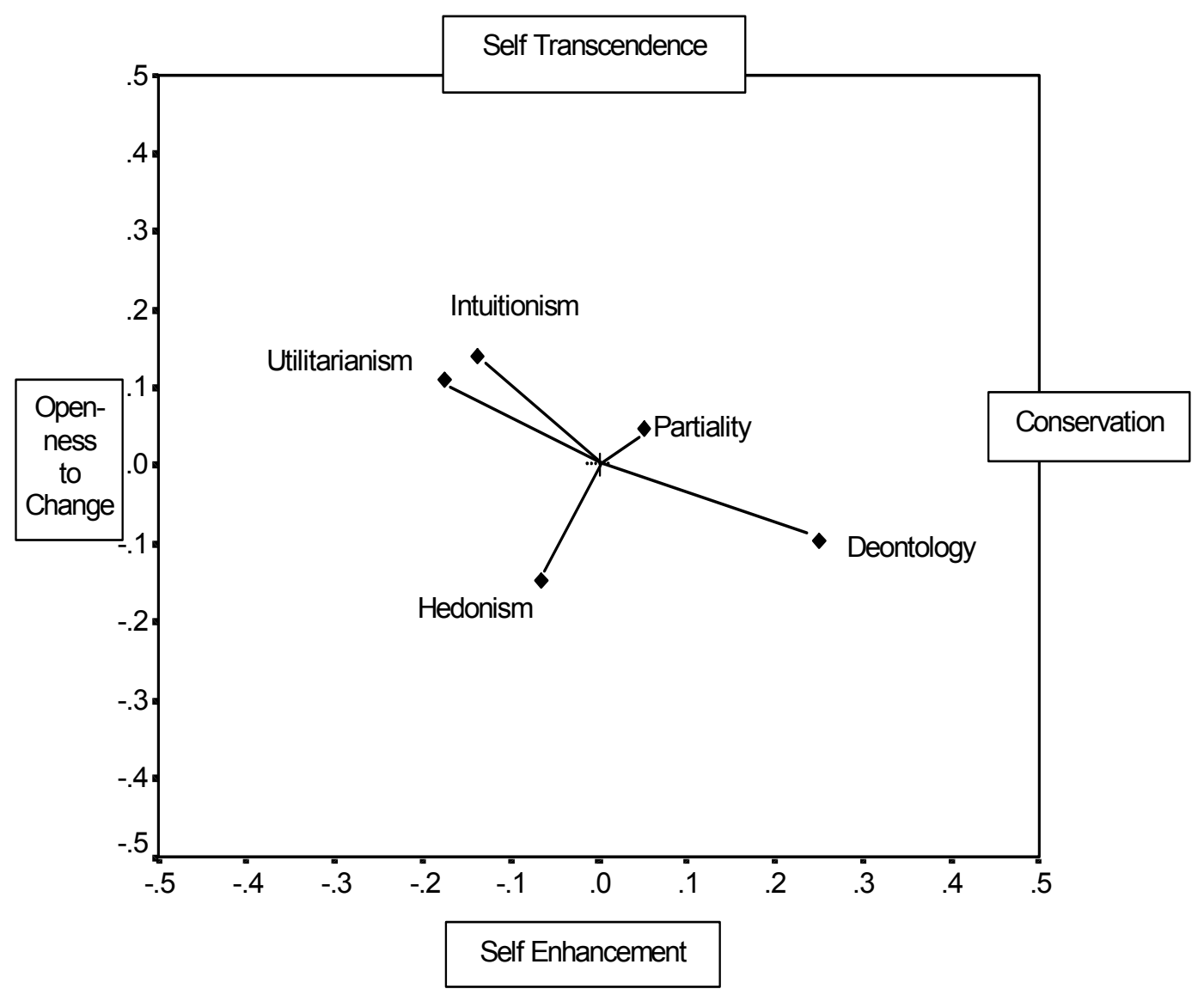

As hypothesized, respondents with self-serving values prefer hedonistic reasoning, and subjects with traditional values prefer the principle of deontology. Subjects promoting universalistic values (self-transcendence) prefer the utilitarian principle of reasoning and intuitionism. Only the principle of partiality did not depend on per- 
sonal values $(r<.10)$. Overall, the dependence of ethical reasoning on personal values validates the individual differences hypothesis 1.

The second hypothesis stated that the usage of ethical principles should depend on the values promoted by the situation. The experimental situation $x$ ethics interaction in Table 1 (source 10) demonstrates the impact in question. To calculate the value content of the actions numerically, their correlational weights from Figure 2 were used. Figure 4 illustrates the correlation of agreement effect scores for each ethical principle per situation (source 10 in Table 1) with the value content of the situation as drawn from Figure 2. The exceeded magnitude of the correlations in Figure 4 is due to their calculation on the level of situations $(N=7)$.

Figure 4: Correlation of situations' values with ethical principle's usage per situation (part of variance due to situation $\mathrm{x}$ ethics, source 10 in Table 1; $N=7$ situations)

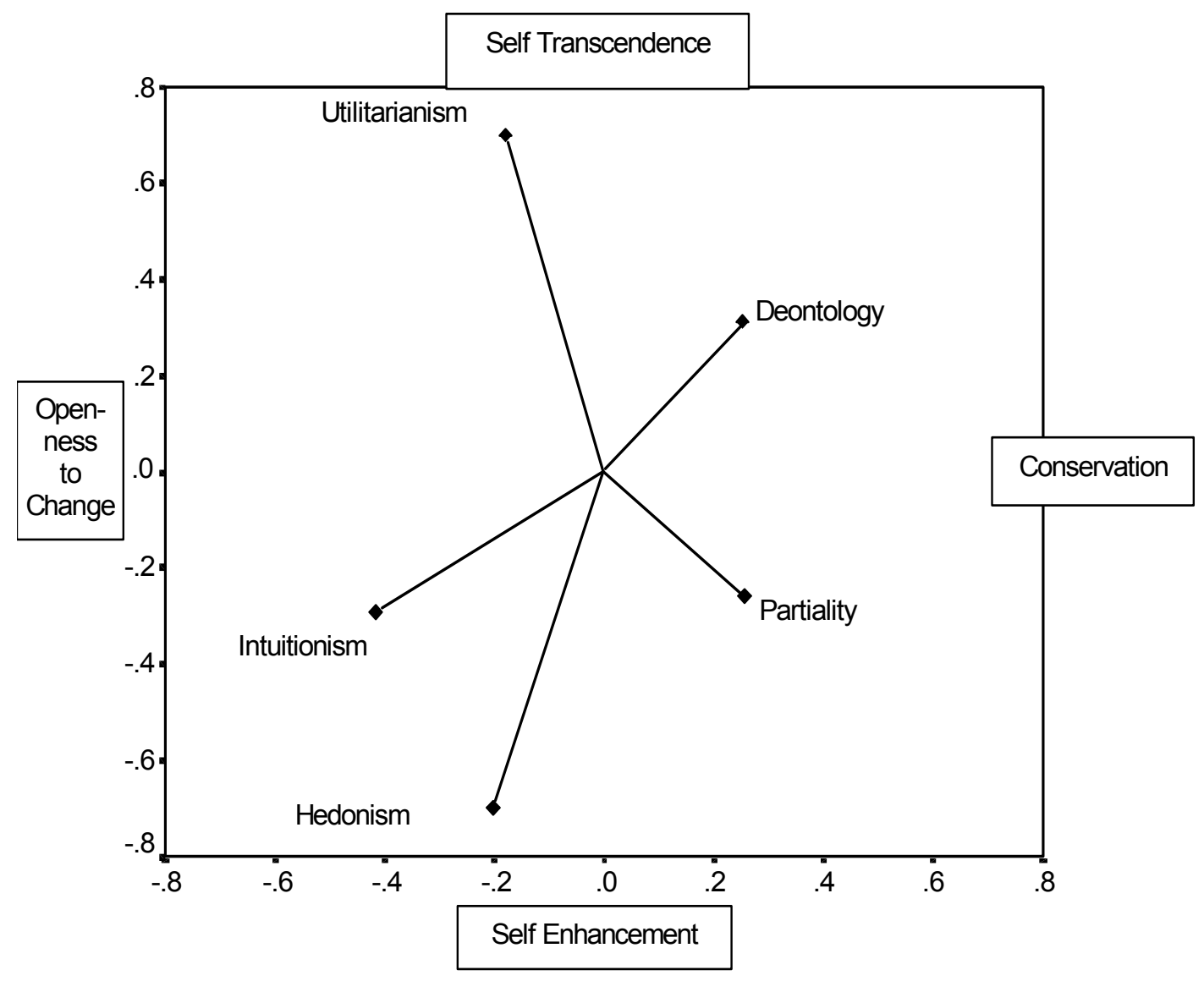

At first glance, Figure 4 shows the expected equivalencies with the pattern in Figure 3. Situations promoting self-transcendence values (e.g., vignette 7 of social peace, see Figure 2) activated the principle of utilitarianism, and situations demanding selfenhancement values inhibit the principle of utilitarianism. Situations expressing be- 
nevolence or traditional values evoked deontological reasoning. The situational approach renders a clearer result regarding the principle of partiality, which was enhanced by security situations. Intuitionalism was used for self-directed actions and hedonistic reasoning was applied in self-enhancement situations.

As the three-way interactions of personal values with the situational values' dependence on ethical principles remain insignificant (source 11 and 12 in Table 1: $F<$ $1, p>$.70), the hypothesized synergetic interaction of person and situation was not found in this study. Person and situation effects remain merely additive.

\section{Discussion}

This investigation addressed relations between personal values, situational values and ethical reasoning. We applied Schwartz's value circle (1992) and analyzed the dependencies of preferences for five ethical principles on personal value preferences and on value-laden situations given in experimentally specified vignettes. Personal diversity in values was fully combined with experimentally controlled situational values. The within-subject design ensured that an analysis of variance could regress agreement with ethical principles to the value content of situations, the value preference of respondents, and the interaction of both.

The correlations illustrated in Figure 3 and 4 indicate that ethical principles are substantially determined by both a person's value orientation and the value content of the situation. The results remain additive, no person $\mathrm{x}$ situation interaction emerges.

By and large, the first two hypotheses were confirmed. Persons striving towards security and tradition preferred the principle of deontology and partiality. Persons with value orientations of self-transcendence and openness to change preferred the principle of utilitarianism and intuitionism. Persons with hedonistic values preferred hedonistic principles. Thus, the examination of personal value systems illustrates the classical conflict between the utilitarian and deontological traditions (cf. Weber, 1958). Substantial effects of the vignette contents support the second hypothesis. Situations promoting universalistic values evoked the principle of consequentialism (utilitarianism). Situations activating benevolence values were related to deontological reasoning. Situations in which actions were motivated by security tended to be justified with the principle of partiality. In situations emphasizing hedonistic values, hedonistic and intuitional reasoning was preferred.

However, comparing Figures 3 and 4, some interesting differences between the effects of situational values and personal value preferences emerge, contradicting a 
perfect functional equivalence of person and situation. This is especially obvious in the case of the principle of intuitionism. For both the personal and the situational variance sources, the relation to openness to change or self-direction maintains. In respect to personal values, however, the principle of intuitionism is more related to universalistic values, and in respect to situations it is more related to the expression of hedonistic values. The preference of universalists for intuitionism could be explained by the aptitude of people with humanistic values in self-perception and their trust in their own feelings (e.g., Tomkins, 1995). The common use of intuitionist reasoning after hedonistic actions may be explained as an acceptance of personal responsibility in the absence of socially justified external causes. Considering, furthermore, the additive nature of both sources, intuitionism is most prominent in justifications regarding self-directed hedonistic actions carried out by people with self-direction and universalistic values. We therefore predict that addressees confronted with a single intuitionist explanation might attribute hedonistic dispositions even in the case of a universalistic orientation of the actor. Thus, our results can account for the challenges of emotional self-regulation and social regulation in moral arguments.

The mere additive nature of our results (no person $x$ situation interaction emerged) facilitates to explain social conflicts due to disagreement on ethical justifications. If people cannot agree on the choice between basic human values, there is little hope for arriving at agreement on controversial issues simply by deliberation and ethical discussion. According to the result of a value dependence of ethical reasoning, it is unlikely that party $A$, holding values different to party $B$, will perceive party $B$ 's ethical principles to be convincing. The dependency of ethical reasoning on personal value systems and the resulting problems may be even stronger in real world behavior. In the experimental setting, the participants were forced to comply with a set of situational positions that might conflict with their deeper personal values. The ordered presentation of the situations, however, assures the smooth blending of situational values. When actions are freely chosen, they may be more in line with personal values (Bardi \& Schwartz, 2003).

The limitations of our experimentally-designed questionnaire study must also be considered. For a questionnaire study, the participant sample size is rather small and enables the discussion of medium effect sizes. However, for an experimental approach and the effect sizes found in our data, the sample-size is quite appropriate. Additionally, the generated heterogeneity of the sample assured the variance in the personal values (see e.g., Schwartz \& Rubel, 2005, in our data self-transcendence could be regressed on age, female sex, and education; traditional values on age and unemployment. The personal values essentially mediated demographic effects on the 
ethical principles (Figure 3). The East-West residences of the subjects remain without effects.

Furthermore, the merely modest reliability of the ethical principles' measures is suboptimal; therefore, the stability of the length of the vectors in Figures 3 and 4 is unclear. They might become more reliable if more than two items were employed to asses each ethical principle (e.g., Witte \& Doll, 1995, used five items per scale). Therefore, we primarily interpret the direction of the vectors. Additionally, the sampling of the situations should be discussed. Limitations emerged in respect to the situational effects in Figure 4. Because only seven situations were presented, the correlation results in Figure 4 are less reliable than the effects of personal values in Figure 3. To obtain the same reliability of personal and situational sources, the samples of persons and situations would need to be of equal size. In laboratory studies, even smaller numbers of situations are usually varied (e.g., Schmitt et al. 2003, 2004 varied two situations; Lönnqvist et al., 2006, varied four). Although limited, the number of seven situations seems justifiable by the motivational limitations of the participants under demand. To ensure a sample of situations representative at least in content, we constructed the situation vignettes according the Schwartz value circle. We assume that the value circle provides a complete representation of situations in the way that it represents all possible content classes of personal value orientations. For the sake of commensurability, we worded the situational vignettes as closely as possible to the values given in Schwartz (1992). By this means, we assured that the vignettes activated values varying systematically across all regions of the value circle. Hence, the abstractness of the situations corresponds to the abstractness of personal values. The lack of feature concreteness of the vignette situations can be seen as a typical limitation of a vignette study. Their abstractedness was a foreseeable consequence of the value's operationalization, and it demands an imaginative role making on the side of the participants. Figure 2 controlled that the vignettes sufficiently express situational values. The overall results provide evidence that the participants were able to make sense of the abstract situations provided.

The fact that the content of the situations represents the whole value circle additionally enables us to identify the acquiescence usually shown by subjects preferring conservation and self-transcendence (benevolence and tradition values). The general linear model (GLM) is a suitable method for separating the sources of variance in the approach of interactionism. If the number of situations will be increased, hierarchical linear modeling might be statistically more adequate (Raudenbush et al., 2002). 
When we relate the results to the discussion of moral principles within moral philosophy, we see that the results support the notion of inherent conflict in the ethical universe. In the second half of the twentieth century, various authors abandoned attempts to construct a unifying system which would integrate different ethical positions (Hampshire, 1983; Larmore, 1987; Nagel, 1979; Weber, 1958). This was deemed an irresolvable conflict between the utilitarian and the deontological traditions (e.g., Weber, 1958). This challenges universality in basic principles of ethical thinking and could undermine the if-then structure of general ethical decisions. In line with the theoretical analyses of ethical principles, the results suggest that the principles are perceived divergently, following the plurality already accepted for values (Schwartz, 1992).

However, plurality as an irresolvable coexistence of incompatible perspectives seems to incrementally receive acceptance only in the case of social or interpersonal diversity. The study therefore was restricted to the social situation of justifications in interpersonal value conflicts. Future analysis might examine intrapersonal value conflicts, its intrapersonal reasoning (Bernard et al., 2003a), and accompanied affects. In this line a bit of incertitude affect came to the fore when our subjects less agreed with all ethic principles applied to specific situations, respectively their imagined value position in situation that did not match their personal values. This - on a lower level already interactionistic - variance source was used as the manipulation check of the vignettes in Figure 2. Justification involvement is a function of the person-situation match.

\section{Conclusions}

The results confirm the dependence of action justification (i.e. the application of ethical principles) on personal and situational values. Orderly conflicts among ethical principles resulted from the plurality of values. Conflicts between ethical principles not only create problems for the development of unifying systems in philosophy but they also hinder the function of everyday moral reasoning, deliberation and interpersonal discourse. Actions based on ethical reasoning intelligible to addressees with similar value orientations are easy to accept. The same justifications are difficult to agree on for addressees who prefer competing values or who are located in different situations. Based on our results, we propose employing the conscious and controlled use of contra-intuitive reasoning in the attempt to resolve social conflicts. The application of ethical principles which usually match the competing values of the other party might evoke better mutual understanding and respect, even if there is no common ground for an agreement on the values themselves. 


\section{References}

Allport, G. W. (1939). Personality: A psychological interpretation. New York: Holt.

Asch, S. E. (1955). Opinions and social pressure. Scientific American, 193, 31-35.

Bardi, A., \& Schwartz, S. H. (2003). Values and behavior: Strength and structure of relations. Personality and Social Psychology Bulletin, 29, 1207-1220.

Baumeister, R. F. (1989). The problem of life's meaning. In D. M. Buss \& N. Cantor (Eds.), Personality psychology: Recent trends and emerging directions (pp. 138-148). New York: Springer.

Beck, L. W. (1989). Immanuel Kant: Foundations of the metaphysics of morals (2nd ed.). Upper Saddle River, NJ: Prentice Hall.

Bernard, M. M., Maio, G. R., \& Olson, J. M. (2003a). Effects on introspection about reasons for values: Extending research on values-as-truisms. Social Cognition, 21, 1-25.

Bernard, M. M., Maio, G. R., \& Olson, J. M. (2003b). The vulnerability of values to attack: Inoculation of values and value-relevant attitudes. Personality and Social Psychology Bulletin, 29, 63-75.

Candee, D., \& Puka, B. (1984). An analytic approach to resolving problems in medical ethics. Journal of Medical Ethics, 2, 61-70.

Cherry, J., \& Fraedrich, J. (2002). Perceived risk, moral philosophy and marketing ethics: Mediating influences on sales managers' ethical decision-making. Journal of Business Research, 55, 951-962.

Feather, N. T. (1990). Reactions to equal reward allocations: Effects of situation gender and values. British Journal of Social Psychology, 29, 315-319.

Forsyth, D. R. (1980). A taxonomy of ethical ideologies. Journal of Personality and Social Psychology, 39 (1), 178-184.

Forsyth, D. R., Nye, J. L.; \& Kelley, K. (1988). Idealism, relativism, and the ethic of caring. Journal of Psychology, 122, 243-248.

Forsyth, D. R., \& Nye, J. L. (1990). Personal moral philosophies and moral choice. Journal of Research in Personality, 24 (4), 398-414. 
Fraedrich, J. P., \& Ferrell, O. C. (1992). The impact of perceived risk and moral philosophy type on ethical decision making in business organizations, Journal of Business Research, 24, 283-295.

Gollan, T., \& Witte, E.H. (2008). „It was right to do it, because ...". Understanding justifications of Actions as Prescriptive Attributions. Social Psychology, 39, 189-196.

Hampshire, S. (1983). Morality and conflict. Cambridge, MA: Harvard University Press.

Hadjistavropoulos, T., Malloy, D. C., Sharpe, D., \& Fuchs-Lacelle, S. (2003). The ethical ideologies of psychologists and physicians: A preliminary comparison. Ethics and Behavior, 13, 97-104.

Heath, R. L. (1976). Variability in value system priorities as decision-making adaptation to situational differences. Communication Monographs, 43, 325-333.

Heider, F. (1958). The psychology of interpersonal relations. New York: Wiley.

Jensen, L., Taylor, A., \& Burton, J. (1981). A factoral study of the moral content components test. Educational and Psychological Measurement, 41, 613-624.

Jost, T. J., Glaser, J., Kruglanski, A. W., \& Sulloway, F. J. (2003). Political conservatism as motivated cognition. Psychological Bulletin, 129, 339-375.

Larmore, C. E. (1987). Patterns of moral complexity. Cambridge: Cambridge University Press.

Lönnqvist, J.-E., Leikas, S., Paunonen, S., Nissinen, V., \& Verkasalo, M. (2006). Conformism moderates the relations between values, anticipated regret, and behavior. Personality and Social Psychology Bulletin, 32, 1469 - 1481.

Lukes, S. (1989). Making sense of moral conflict. In N. L. Rosenblum (Ed.), Liberalism and the moral life (pp. 127-142). Cambridge, MA: Harvard University Press.

Maio, G. R., \& Olson, J. M. (1998). Values as truisms: Evidence and implications. Journal of Personality and Social Psychology, 74 (2), 294-311.

Milgram, S. (1963). Behavioral study of obedience. Journal of Abnormal and Social Psychology 67, 371-378.

Nagel, T. (1979). Mortal questions. Cambridge: Cambridge University Press. 
Parfit, D. (1984). Reasons and persons. Oxford: Clarendon.

Raudenbush, S. W. \& Bryk, A. S. (2002, 2nd edition). Hierarchical linear models: Applications and data analysis methods. London: Sage.

Riesman, D. (1950). The lonely crowd. New Haven: Yale University Press.

Rohan, M.J. (2000). A rose by any name: The values construct. Personality and Social Psychology Review, 4, 255-277.

Rokeach, M. (1973). The nature of human values. New York: Free Press.

Schmitt, M., Eid, M., \& Maes, J. (2003). Synergistic person x situation interaction in distributive justice behavior. Personality and Social Psychology Bulletin, 29, 141-147.

Schmitt, M. \& Sabbagh, C. (2004). Synergistic person x situation interaction in distributive justice judgment and allocation behavior. Personality and Individual Differences, 37 , 359-371.

Schwartz, S. H. (1992). Universals in the content and structure of values: Theoretical advances and empirical tests in 20 countries. In M. Zanna (Ed.), Advances in experimental and social psychology (Vol. 25, pp. 1-65). Orlando, FL: Academic.

Schwartz, S. H. (2011). Studying values: Personal adventure, future directions. Journal of Cross-Cultural Psychology, 42, 307-319.

Schwartz, S. H., \& Bilsky, W. (1987). Toward a psychological structure of human values. Journal of Personality and Social Psychology, 53, 550-562.

Schwartz, S. H. \& Rubel, T. (2005). Sex differences in value priorities: Cross-cultural and multimethod studies. Journal of Personality and Social Psychology, 89, 1010-1028.

Strack, M. (2004). Sozialperspektivität [Social Metaperception]. Goettingen, FRG: Universitätsverlag.

Strack, M., \& Gennerich, C. (2007). Erfahrung mit Forsyths ,Ethic Position Questionnaire“ (EPQ) [Experiences with Forsyth's ,Ethic Position Questionnaire' (EPQ)] (Research report of the group "Verantwortung, Gerechtigkeit und Moral“ No. 167). Germany: Psychological documents. Download: http://psydok.sulb.uni-saarland.de/volltexte/2007/953/ 
Stirner, M. (1995). The ego and its own (D. Leopold \& S. T. Byington, Trans.). Cambridge, UK: Cambridge University Press. (Original work published 1844)

Tedlock, P. E. (1986). A value pluralism model of ideological reasoning. Journal of Personality and Social Psychology, 50 (4), 819-827.

Weber, M. (1958). Politics as a vocation. In H.H. Gerth \& C. Wright Mills (Eds.), From Max Weber: Essays in sociology (pp. 77-128). New York: Oxford University Press. (Original work published 1918)

Witte, E. H., \& Doll, J. (1995). Soziale Kognition und empirische Ethikforschung: Zur Rechtfertigung von Handlungen [Social cognition and empirical ethics research]. In E. H. Witte (Ed.), Soziale Kognition und empirische Ethikforschung (97-115). Lengerich, Germany: Pabst. 


\section{Appendix}

\section{Appendix 1}

Each of the seven vignettes was followed by the 10 statements for their justification (translations)

The seven vignettes:

(1) "You get involved in an argument. You are arguing for social justice and more integrity in order to protect the disadvantaged against the unjust enrichment and desire for power of the individval."

(2) "You get involved in an argument. You are on the side of tolerance and open-mindedness while the other party seeks to save face in public."

(3) "You get involved in an argument because you want to try out new ways instead of abandoning good ideas in order not to offend older generations."

(4) "You get involved in an argument. You are expected to be more humble and to demonstrate an unrealistic romanticism for nature. You bring up the improvement of standards of living and are able to come to agreement on modern technical achievements."

(5) "You get involved in an argument where the other party overemphasizes egalitarianism for and openness towards all and everybody. You took your authority and serve up clear circumstances."

(6) "You get involved in an argument. The other party is willing to accept irresponsible risks while seeking short-term gain. You argue for the conservation of approved traditions."

(7) "You get involved in an argument because you assert your position for stability and a peaceful society whereas the other party only seeks advantages for themselves. Which of the following justifications would you choose?"

The statements for justification (ethical principles) to be assessed on a five-point rating scale (1 rather no to 5 rather yes)

(deontological)

"It is my duty towards society to do so."

"My guidelines are the principles of universal validity" (utilitarian)

"It is clear that in the long run it is the best for everyone."

"Looking at the overall consequences, this is the better choice for all concerned." (particular)

"I feel personally committed and must take a stand."

"In my situation I'm committed to this behavior."

(intuitional)

"Intuitively I feel this position is the right one."

"I simply have to act in this way."

(hedonistic)

"This is best for me."

"Everyone has a right to hold this position." 
Appendix 2: The 14BiPole-Value questionnaire

Instructions: The following 14 value pairs are not necessarily opposites; they may express complementary tendencies under some circumstances. Please indicate your own personal values. Rating a value with an answer of "2" indicates "clearly more important than the other value", an answer of "1" indicates ",ends to be preferred over the other" and „0" indicates equal weight for both values. Please make only one mark in each row.

\begin{tabular}{|c|c|c|c|c|c|c|}
\hline $\begin{array}{c}\text { EQUALITY } \\
\text { (equal opportunity for all) }\end{array}$ & 2 & 1 & 0 & 1 & 2 & $\begin{array}{c}\text { AUTHORITY } \\
\text { (the right to lead or } \\
\text { command) }\end{array}$ \\
\hline $\begin{array}{l}\text { SOCIAL POWER } \\
\text { (control over others, } \\
\text { dominance) }\end{array}$ & 2 & 1 & 0 & 1 & 2 & $\begin{array}{l}\text { SOCIAL JUSTICE } \\
\text { (correcting injustices, } \\
\text { care for the weak) }\end{array}$ \\
\hline $\begin{array}{l}\text { SOCIAL ORDER } \\
\text { (stability of society) }\end{array}$ & 2 & 1 & 0 & 1 & 2 & $\begin{array}{c}\text { EXCITING LIFE } \\
\text { (stimulating experiences) }\end{array}$ \\
\hline $\begin{array}{l}\text { WEALTH } \\
\text { (material possessions, } \\
\text { money) }\end{array}$ & 2 & 1 & 0 & 1 & 2 & $\begin{array}{l}\text { UNITY WITH NATURE } \\
\text { (fitting into nature) }\end{array}$ \\
\hline $\begin{array}{c}\text { POLITENESS } \\
\text { (courtesy, good manners) }\end{array}$ & 2 & 1 & 0 & 1 & 2 & $\begin{array}{c}\text { CREATIVITY } \\
\text { (uniqueness, imagination) }\end{array}$ \\
\hline $\begin{array}{l}\text { ENJOYING LIFE } \\
\text { (fulfilment of wishes) }\end{array}$ & 2 & 1 & 0 & 1 & 2 & $\begin{array}{l}\text { A WORLD AT PEACE } \\
\text { (free of war and conflict) }\end{array}$ \\
\hline $\begin{array}{l}\text { BROAD-MINDED } \\
\text { tolerant of different ideas and beliefs }\end{array}$ & 2 & 1 & 0 & 1 & 2 & $\begin{array}{l}\text { PRESERVING PUBLIC IMAGE } \\
\text { (protecting face) }\end{array}$ \\
\hline $\begin{array}{c}\text { HUMBLE } \\
\text { (modest, self-effacing) }\end{array}$ & 2 & 1 & 0 & 1 & 2 & $\begin{array}{l}\text { INFLUENCIAL } \\
\text { (having an impact on people } \\
\text { and events) }\end{array}$ \\
\hline $\begin{array}{c}\text { HONEST } \\
\text { (genuine, sincere) }\end{array}$ & 2 & 1 & 0 & 1 & 2 & $\begin{array}{l}\text { SUCCESSFUL } \\
\text { (achieving goals) }\end{array}$ \\
\hline ENJOYING LIFE & & & & & & DEVOUT \\
\hline $\begin{array}{l}\text { (enjoying food, sex, leisure, } \\
\text { etc.) }\end{array}$ & 2 & 1 & 0 & 1 & 2 & $\begin{array}{l}\text { (holding to religious faith and } \\
\text { belief) }\end{array}$ \\
\hline $\begin{array}{c}\text { RESPECT FOR TRADITION } \\
\text { (preservation of time-honoured } \\
\text { customs) }\end{array}$ & 2 & 1 & 0 & 1 & 2 & $\begin{array}{l}\text { A VARIED LIFE } \\
\text { (filled with challenge, } \\
\text { novelty, and change) }\end{array}$ \\
\hline $\begin{array}{c}\text { DARING } \\
\text { (seeking adventure, risk) }\end{array}$ & 2 & 1 & 0 & 1 & 2 & $\begin{array}{c}\text { OBEDIENT } \\
\text { (dutiful, meeting obligations) }\end{array}$ \\
\hline $\begin{array}{l}\text { CHOOSING OWN GOALS } \\
\text { (selecting own purposes) }\end{array}$ & 2 & 1 & 0 & 1 & 2 & $\begin{array}{l}\text { HONORING OF PARENTS AND } \\
\text { ELDERS (showing respect) }\end{array}$ \\
\hline $\begin{array}{c}\text { OPENNESS } \\
\text { (cosmopolitan orientation, } \\
\text { advocate of diversity) }\end{array}$ & 2 & 1 & 0 & 1 & 2 & $\begin{array}{l}\text { CONTROL OVER UNCERTAINTY } \\
\text { (control over events } \\
\text { and their development) }\end{array}$ \\
\hline
\end{tabular}


About the authors:

Dr. Micha Strack (corresponding author) is associate professor at the Georg-AugustUniversity Göttingen, Germany. Her primary research interests focus on the social psychology of values and applied statistics.

Address for correspondence: Dr. Micha Strack, Georg-Elias-Müller-Institut of Psychology, Gosslerstrasse 14, 37073 Göttingen, Germany.

E-mail: mstrack@uni-goettigen.de

Dr. Carsten Gennerich is a professor at the University of Applied Science Evangelische Hochschule Darmstadt, Germany. He is also involved in the ISREV (International Seminary for Religious Education and Values). His research interests include the social psychology of values, parish education, and religious education. 